\title{
Construction of Temporary Field of Play Facilities for Gold Coast Commonwealth Games ${ }^{+}$
}

\author{
Jarrod Hill \\ SPORTENG, Hawthorn East, VIC 3123, Australia; jarrod.hill@sporteng.com.au; Tel.: +61-040-918-3240 \\ + Presented at the 12th Conference of the International Sports Engineering Association, Brisbane, \\ Queensland, Australia, 26-29 March 2018.
}

Published: 22 February 2018

\begin{abstract}
The planning for major international sporting events such as the Olympic Games and Commonwealth Games require the use of a range of Field of Play facilities. Often these are required to be temporary overlay installations due to the cost of constructing new standalone facilities. The planning for the 2018 Gold Coast Commonwealth Games included the construction of several permanent new build facilities that would be retained as legacies for the Gold Coast and Brisbane regions. The games will also include several temporary overlay Field of Play facilities; these are the competition and warm-up athletics track and field and the beach volleyball facilities. The design of such temporary overlay sites need to ensure the construction adheres with the governing sport body as well as providing quick and economical construction methodology. This paper provides an overview of the design for the temporary Field of Play facilities.
\end{abstract}

Keywords: athletics; volleyball; temporary; legacy; Commonwealth; Games: Field of Play

\section{Introduction}

The world is scattered with poor examples of post-game legacy facilities for global sporting competitions. Countries often commit large sums of money for the construction of new facilities for events such as the Olympic Games, Commonwealth Games and World Cups. Many world class facilities are built in regions that do not have the local demand to keep the facility operational and/or are too expensive to maintain post-event.

You don't have to look too far for examples; Brazil 2014 FIFA World Cup, Rio's 2016 Olympic Games, Athens 2004 Olympic Games (Figure 1), Sochi's 2014 Winter Olympics; all are littered with facilities that have not been used post-event and subsequently have deteriorated.

In recent years there has been a greater push to either construct temporary facilities within existing operational sites that were already self-sufficient pre-event or to repurpose an existing site that can be used for the event and then utilised as an upgraded facility post-event. The cost to 'bumpin' a temporary venue or to renovate/repurpose an existing facility is often significantly cheaper than building a new facility.

The Glasgow 2014 Commonwealth Games is an example of a global sporting events relating to successful usage of facilities post-event. The Glasgow Games also consisted of a couple of 'bump-in' overlay facilities such as the athletics track and field facility which was constructed within the Hampden Park stadium.

The upcoming 2018 Commonwealth Games (Games) will include a combination of newly constructed facilities (velodrome and swimming pool), repurposed existing facilities (Village Roadshow studios for boxing, table tennis and squash) and temporary overlay Field of Play facilities (athletics track and field and beach volleyball facilities).

This paper provides an overview for the design and construction of two of the proposed temporary overlay Fields of Play facilities: athletics track and field and beach volleyball facilities. 


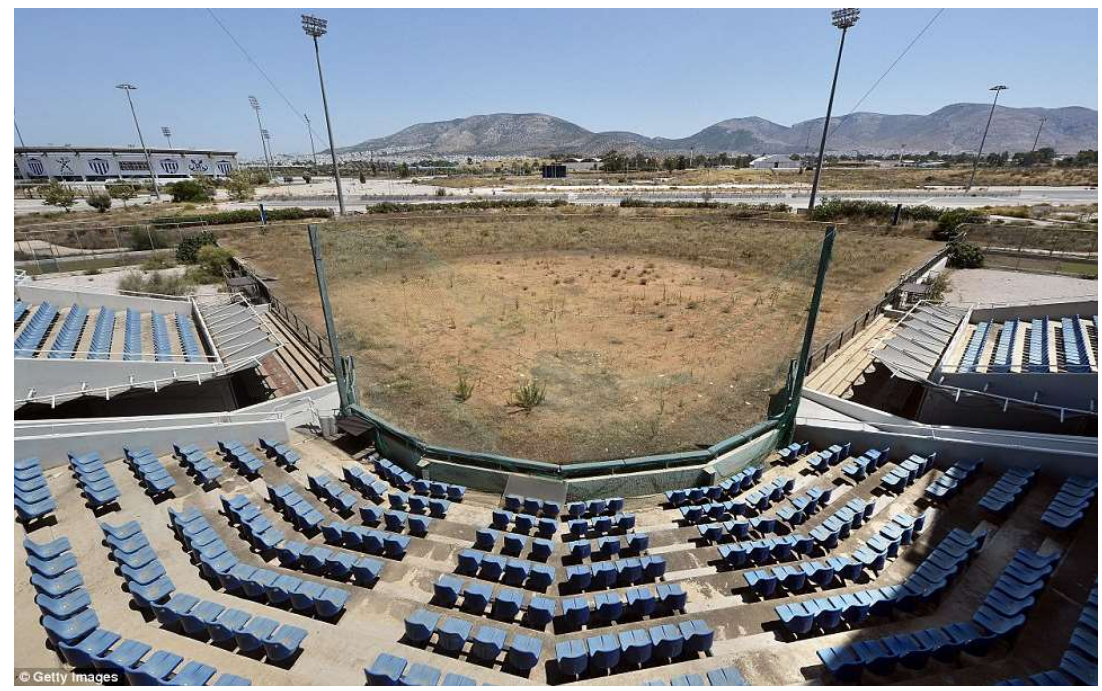

Figure 1. This facility was used to host the 2004 Athens Summer Olympics Baseball (Credit: Daily Mail).

\section{Sites}

\subsection{Athletics Track and Field Facilities}

Carrara Stadium will host the opening and closing ceremonies to be hosted along with the athletics track and field events. The Carrara Stadium Field of Play (FoP) currently consists of a natural turf oval. The length of the existing FoP does not allow for a fully compliant International Association of Athletics Federation (IAAF, Monte Carlo, Monaco) athletics track to be constructed without the removal of the northern terrace of the stadium structure. Foresight during the initial design of the stadium made allowance for the construction of a temporary northern stand to allow for a future athletics track overlay.

\subsection{Beach Volleyball Facility}

Coolangatta Beach will be the site for the beach volleyball event. The competition beach volleyball facility will be constructed on a grassed landscaped area adjacent to the Coolangatta Surf Club. The warm-up courts would be constructed on the beach. Like the athletics track and field facility, the beach volleyball facility will be a temporary facility with the intention to minimize the impact on the existing site to enable ease of deconstruction and re-establishment of the existing site conditions.

\section{Project Requirements}

\subsection{Athletics Track and Field Facilities}

The construction of the Games athletics track is required to meet the following key requirements:

- Adherence to IAAF dimensions, surface levels and tolerances

- Retain the above for a period no longer than 4 months due to the short duration of the Games

- Minimise the extent of construction works to occur within the stadium

- Employ a construction technique that will enable efficient removal of the track and field facility and re-establishment of the natural turf playing surface for the 2018 AFL season (which is being impacted by the Games).

\subsection{Beach Volleyball Facility}

The construction of the Games beach volleyball facility is required to meet the following key requirements: 
- The beach volleyball facility must comply with International Volleyball Federation (FIVB, Paris, France) dimensions

- Field of Play sand must meet the specifications stipulated by FIVB

- Minimise impact on the existing in-ground services

- Provision of a temporary FoP deck which can be deconstruct promptly after the Games.

\section{Design Solution}

\subsection{Athletics Track and Field Facilities}

Typical construction of an athletics track pavement would consist of a road like pavement and would have a design life of 20 years. Over this period the required IAAF surface levels and tolerances would be maintained. However, this permanent construction is expensive and has a lengthy construction period. It also has a long deconstruction period should the site be required to be converted back to the pre-Games condition.

The design for the temporary athletics track and field facility is based on the similar philosophy adopted for the 2006 Melbourne Commonwealth Games athletics track constructed within the MCG (Figure 2). The design utilises the existing in-ground infrastructure (i.e. drainage and irrigation) and the natural bearing capacity of the existing playing surface rootzone sand to efficiently construct the temporary athletics track pavement while minimising construction works.

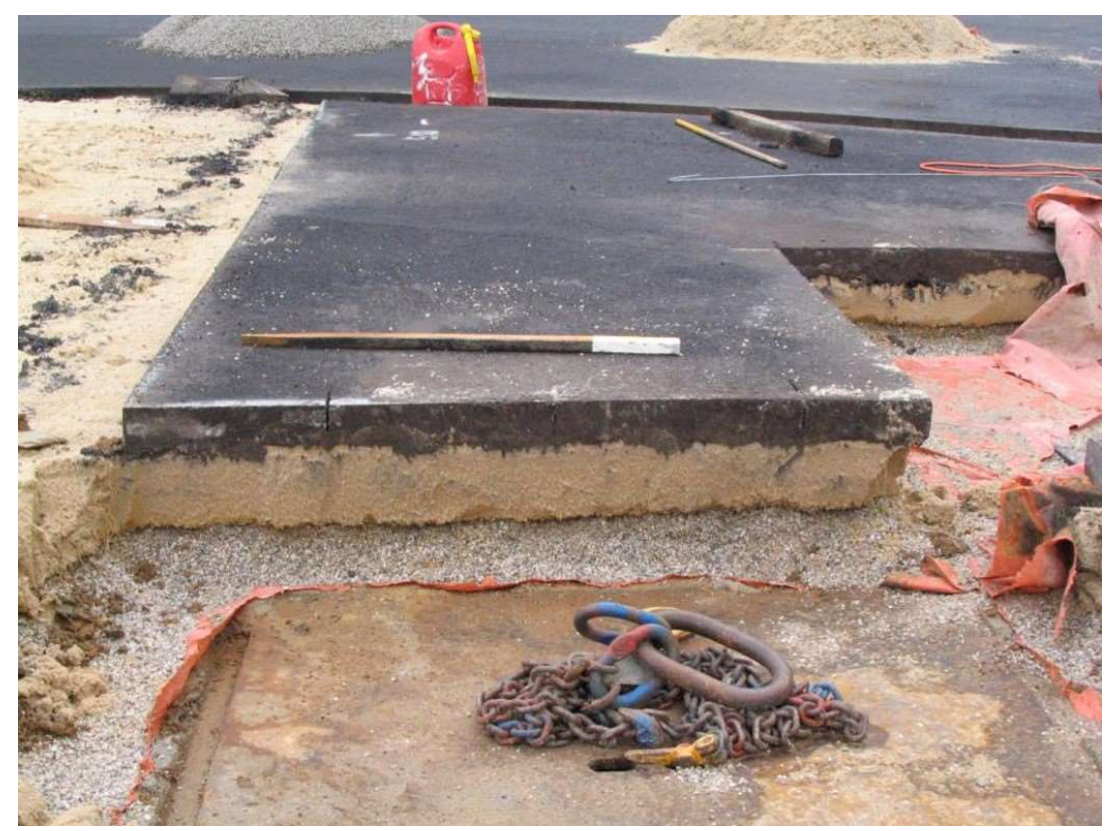

Figure 2. 2004 Melbourne Commonwealth Games temporary track pavement profile.

Removal of the organic layer (approximately 100-150 mm thick) from the existing natural turf playing surface will expose the underlying organic-free rootzone sand layer (Figure 3). The existing oval playing surface shape is domed and is not conducive for an athletics track surface which grades in the opposite direction and falls from the outside lanes to the natural turf infield creating a concave dish-like shape. The exposed rootzone sand is required to be reshaped to achieve the required levels and grades for the construction of the temporary athletics track pavement. 


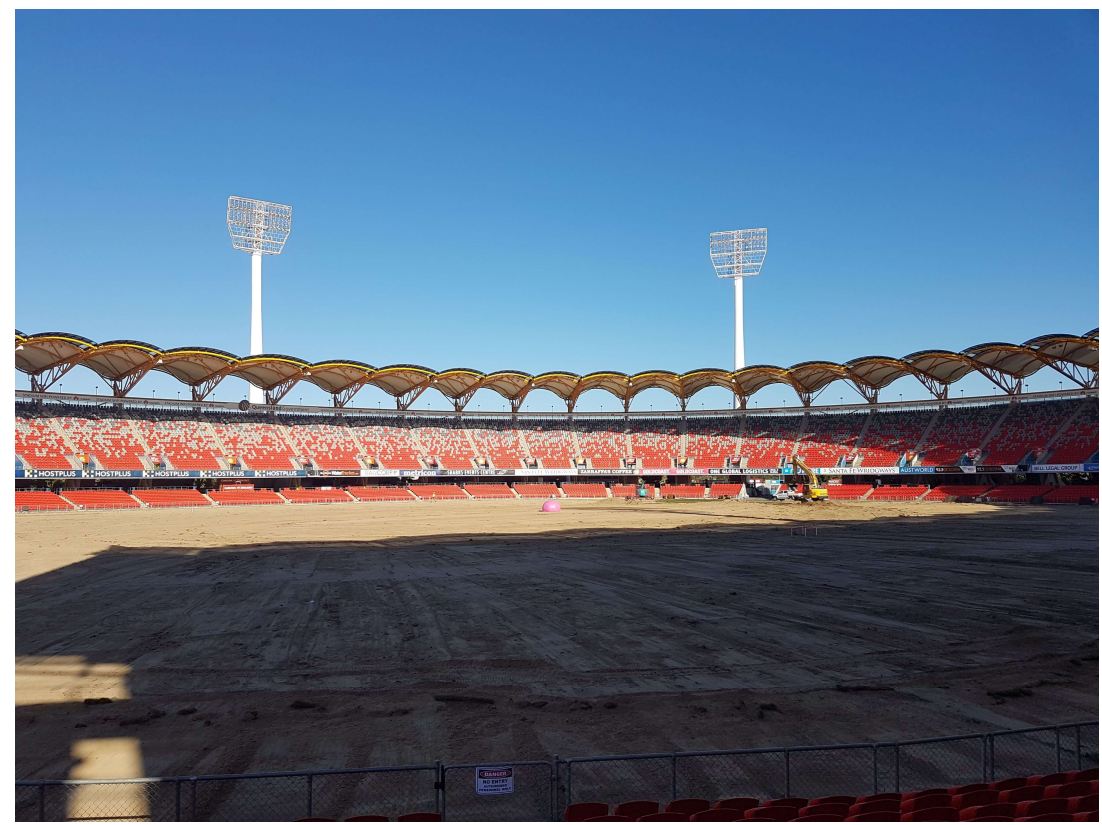

Figure 3. Stripped surface of Carrara Stadium prior to reshaping.

The temporary pavement will be constructed on the reshaped subgrade layer. A geotextile will be laid over the rootzone sand to improve the stability of the sand. This will then enable the granular crushed rock pavement to be placed and compacted. This layer is thinner than a typical track pavement due to the short design life required. On top of the crushed rock layer, two layers of asphalt will be paved to ensure the required tolerances are achieved; a base layer and a control/wearing course layer (Figure 4).

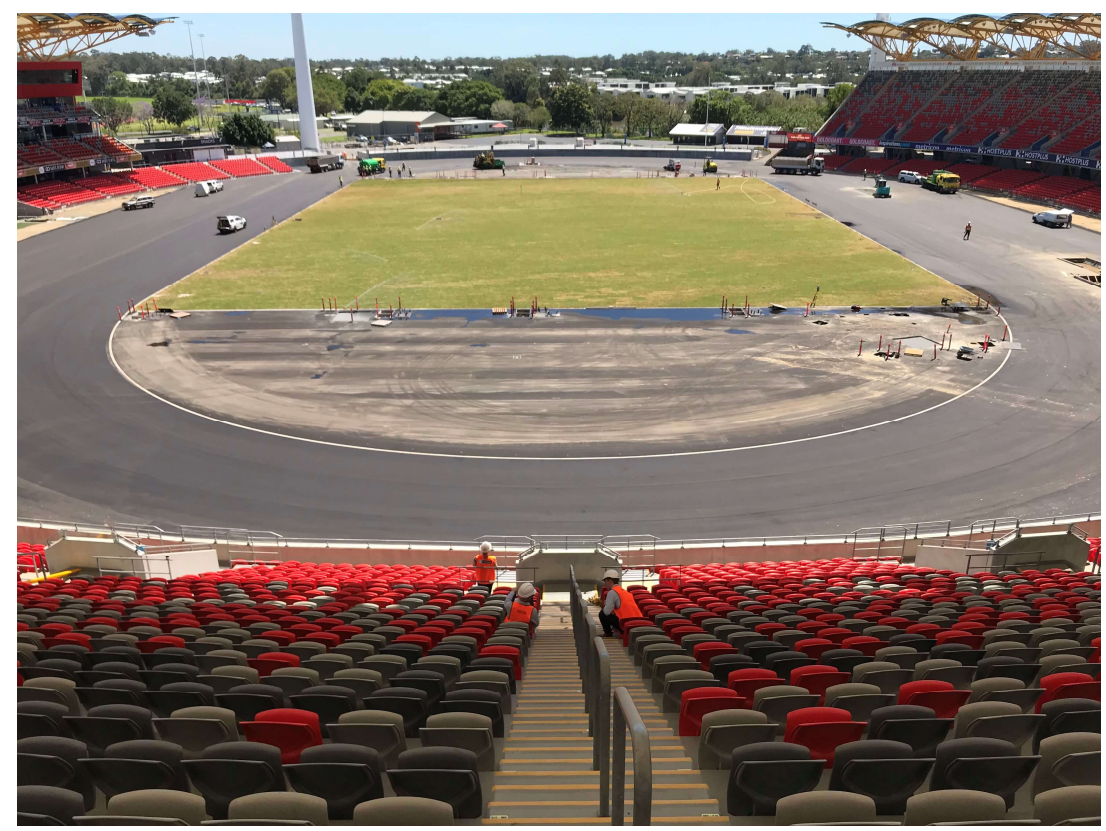

Figure 4. Nearing completion of competition track asphalt works at Carrara Stadium.

This pavement design was validated 6 months before the Games through a pavement trial in the adjacent field (Figure 5). The pavement trial tolerances were checked post-curing of the asphalt layer and then exposed to the multiple passing of loaded trucks to monitor the tolerances under heavy vehicular traffic (Figure 6). The tolerances were checked after the vehicle loading and the tolerances were still IAAF compliant. 


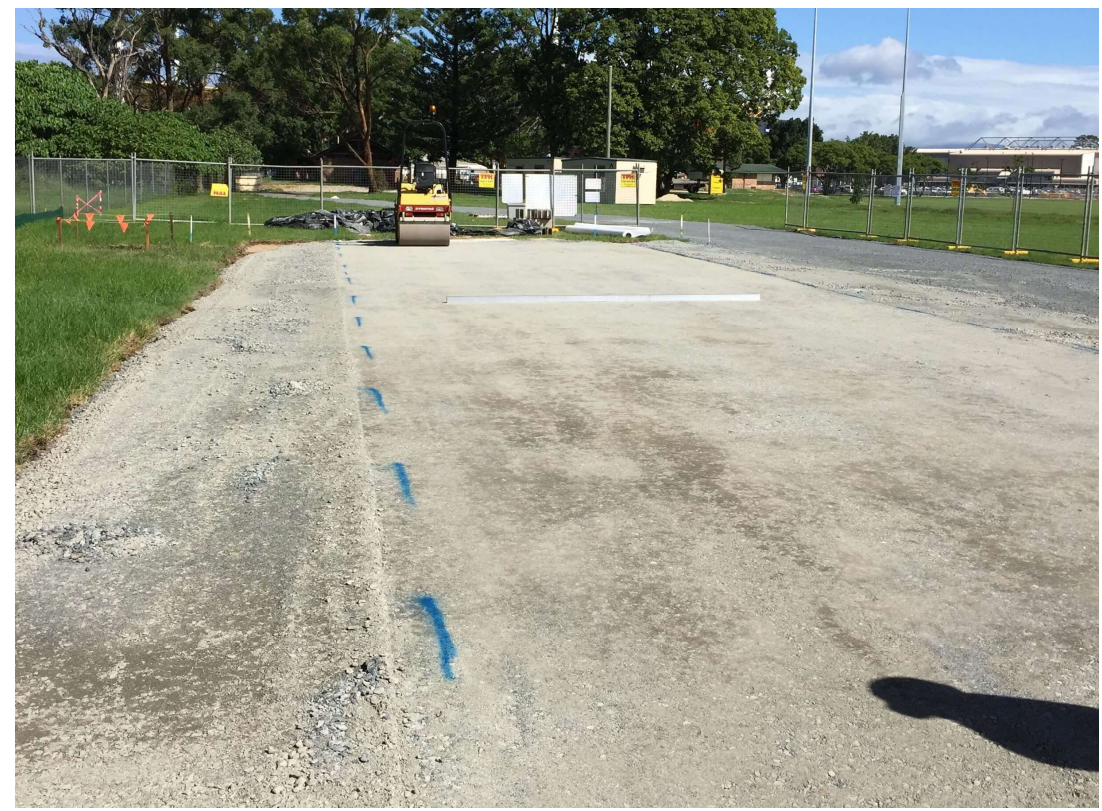

Figure 5. Construction of pavement trial.

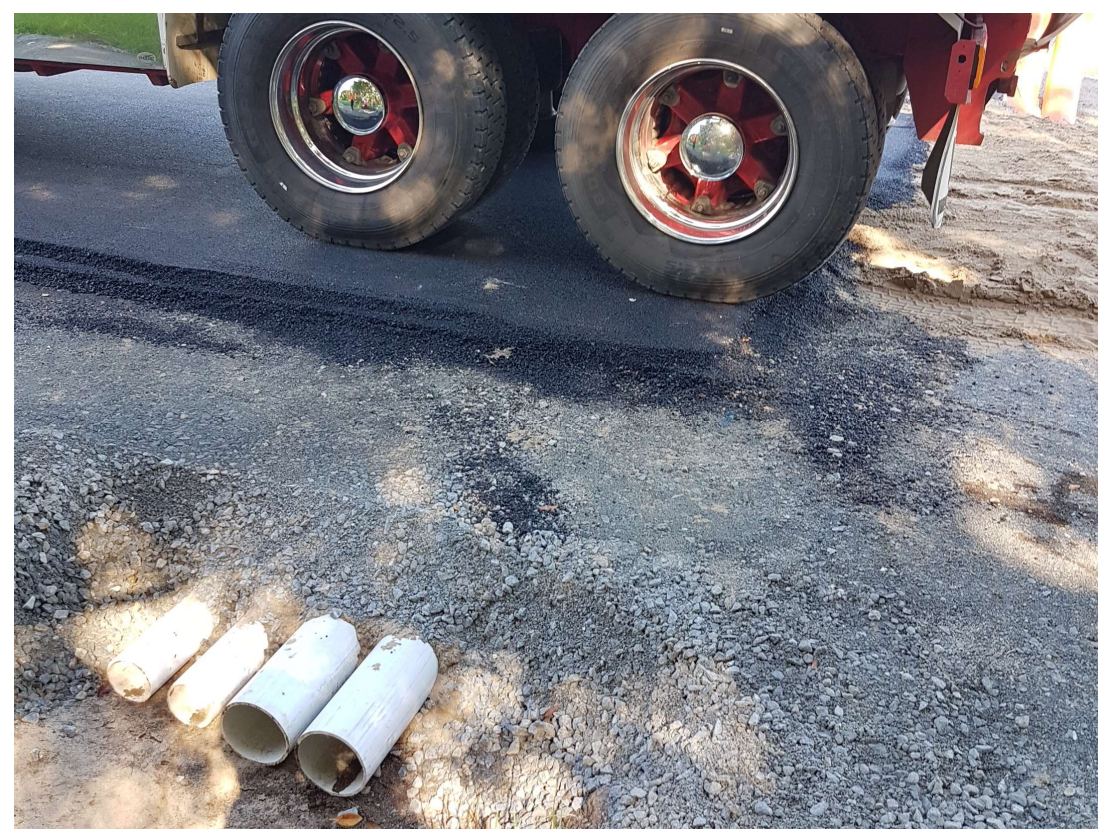

Figure 6. Testing of pavement trial.

The athletics track and field drainage will discharge into the existing oval drainage pipework. Where there are no collector pipes within the vicinity of a required drainage discharge point, the drainage for most of the field event elements will utilise the free draining properties of the rootzone sand layer which will be located beneath the temporary pavement.

The existing irrigation for the Carrara Stadium natural turf surface will be utilised for the athletics track turf infield. The irrigation system ring main and lateral pipes across the oval will be retained beneath the proposed track surface. Sprinklers located beneath the footprint of the athletics track and non-competition pavement will be removed and capped within the rootzone sand layer. The sprinklers located within the footprint of the athletics track turf infield will be modified and utilised to maintain the turf during the Games.

The in-ground services (i.e., electrical, communication, data, etc.) conduits will be trenched into the existing rootzone cover and as such will have minimal cover (less than $300 \mathrm{~mm}$ ). Due to the reduced cover over the conduits, protection boards will be placed directly over the placed conduits 
to provide the required mechanical protection (Figure 7). In several cases the minimal cover conduits will cross beneath the athletics track. These conduits will have as less than $200 \mathrm{~mm}$ cover in some locations due to the reverse cross-fall of the athletics track to that of the existing rootzone sand. To verify that the protection boards over the conduits would withstand the compaction works on the overlying crushed rock layer and the paving of the asphalt layer, a section of the pavement trial included conduits installed with protection boards. This was successfully verified in the pavement trial.

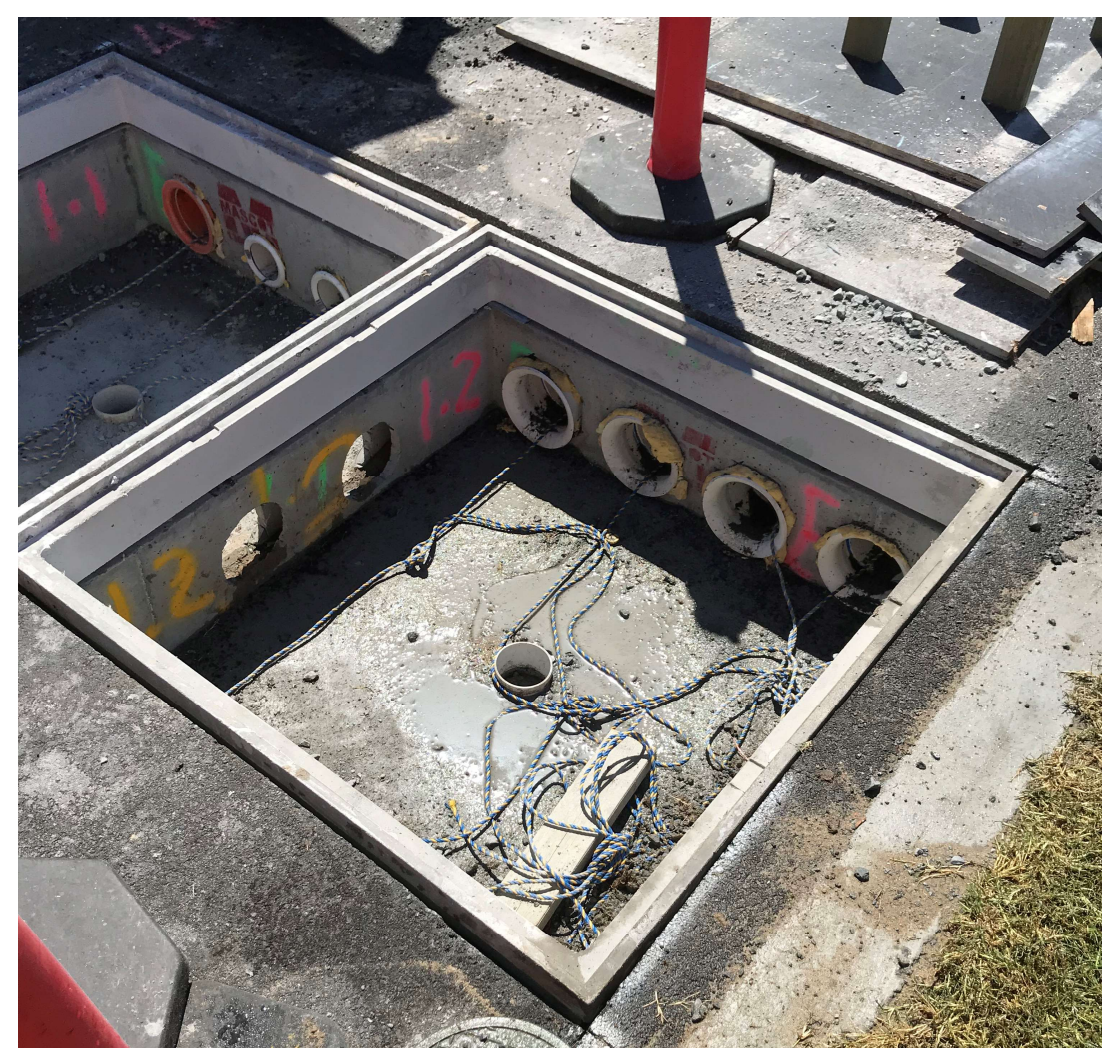

Figure 7. Mechanically protected shallow in-ground service conduits and pits.

\subsection{Beach Volleyball Facility}

Several design solutions were investigated for the construction of the temporary facility for the beach volleyball event. These included:

- $\quad$ Sand bags around the perimeter of the deck, backfilled with FIVB approved sand and modular deck placed on sole-plates directly on the sand

- Variable height screw jacks with modular deck

- Stumps and timber frame with modular deck

- Conventional construction scaffolding with modular deck

- $\quad$ Event scaffolding system.

Not only did the solution need to be cost effective and quick to construct, but it also needed to be adjustable and flexible to account for the fall across the site.

All options were considered and the pros and cons determined for comparison. Two options were modeled in detail and of these two options the event scaffolding system was selected.

The event scaffolding system can have a minimum depth of $350 \mathrm{~mm}$ (approximately) and can extend to a height of approximately $1500 \mathrm{~mm}$. The added benefit is that the system has adjustable height base collars which can provide flexibility to accommodate the fall across the site. The event scaffolding also comes with a built-in decking structure which removes the need for a separate deck module. 
The beach volleyball FoP will be constructed by enclosing the FIVB approved sand with a temporary rectangular tank-like structure. The structure will be constructed independently to the event scaffolding as to not transfer lateral loads onto the scaffold system.

To minimise impact on the site and to make construction and demobilisation efficient, there will be no excavation required for the structure or the FoP. Drainage of the deck and FoP will revert to the current site drainage which utilizes the high infiltration rate of the natural sand profile of the grassed space.

\section{Post-Games Legacy}

Prior to the Games, the organising committee responsible for the delivery of the facilities, the Games bidding team identified what facilities were required post-Games to be used by the local community as a legacy, and which facilities would become white elephants should they be retained post-Games.

During this stage it was identified that both the athletics track and field and the beach volleyball facilities were not required post-Games. The competition track within Carrara Stadium couldn't be retained as it was required to be converted back to a natural turf oval. The Gold Coast already has several athletics tracks that had recently been refreshed in the lead up to the Games so the retention of the warm-up track and field facility as a legacy post-Games was considered a redundant element. It was therefore decided that the athletics track rubber surface from both the competition track and the warm-up track would be removed post-Games and used at another venue or several venues. Therefore the product needed to be an IAAF approved prefabricated product that would allow for the surface to be carefully removed after the game, rolled up and transported to another location suitable for use. Past industry experience of similar removal process suggests that around $80 \%$ of the track surface is salvageable for reuse. The two tracks combined would be sufficient for a new track facility or the surface could be distributed to several schools and other sporting clubs for sprint tracks or similar. The final decision on where the salvaged product will be reused has yet to be confirmed.

There will be some minor works associated with the external civil works for Carrara Stadium that will be retained as legacy items. These include:

- Widening of vomitory to stadium arena

- Increase of hardstand surface around the external stadium concourse

- Vehicle/pedestrian crossings.

The Field of Play sand from the beach volleyball facility will be spread across the adjacent beach to help improve the levels of the beach. Other than this there will be no permanent legacy associated with the beach volleyball facility.

(C) 2018 by the authors. Licensee MDPI, Basel, Switzerland. This article is an open access article distributed under the terms and conditions of the Creative Commons Attribution (CC BY) license (http://creativecommons.org/licenses/by/4.0/). 